\title{
The Strategy of Universal-Design Thinking in Architecturally Innovative Product Development
}

\author{
Chenhui Gao ${ }^{1}$, Kai-Chieh Lin ${ }^{2, *}$ and Zheng-Yi Wu ${ }^{2}$ \\ 1 The Graduate Institute of Design Science, Tatung University, Taipei 104, Taiwan; redchange@126.com \\ 2 Department of Industrial Design, Tatung University, Taipei 104, Taiwan; chrisgod05@gmail.com \\ * Correspondence: kclin@gm.ttu.edu.tw
}

Citation: Gao, C.; Lin, K.-C.; Wu, Z.-Y. The Strategy of Universal-Design Thinking in Architecturally Innovative Product Development. Processes 2021, 9, 2254. https://doi.org/10.3390/pr9122254

Academic Editor: Arkadiusz Gola

Received: 29 November 2021 Accepted: 13 December 2021 Published: 14 December 2021

Publisher's Note: MDPI stays neutral with regard to jurisdictional claims in published maps and institutional affiliations.

Copyright: (c) 2021 by the authors. Licensee MDPI, Basel, Switzerland. This article is an open access article distributed under the terms and conditions of the Creative Commons Attribution (CC BY) license (https:// creativecommons.org/licenses/by/ $4.0 /)$.

\begin{abstract}
Universal design, as an important concept in product development, has been gradually implemented in various industries and firms, but most of the applications are aimed at the incremental innovation of product design. However, considering the differentiation of product types, the design factors are varied and not precise, which makes it difficult to effectively implement the existing universal-design principles in specific product designs when facing architecturally innovative product development, which leads to an increasing amount of time and resources. This study, with an umbrella stand as an example, proposes to design a new universal-design scale by combining the attributes of the umbrella stand, the existing universal-design principles and the usability principles at the beginning of the design. Then, through interviews and user surveys, cluster analysis is used to screen the products and refine the design factors. In addition, with the Quantification Type I, the universal-design principles and design factors are matched effectively in order to obtain the weight differences of the product design factors and eliminate unsuitable design factors, in order to guide product design. Finally, the universal umbrella-stand-design case is completed for verification. The results show that the universal umbrella stand has been significantly improved in the evaluation of universal-design principles. In the future design, architecturally innovative products with inaccurate design factors can also use this process to complete the design and development of the target product, and to significantly enhance the universal-design evaluation of the product.
\end{abstract}

Keywords: universal design; design factors; architecturally innovative

\section{Introduction}

Universal-design thinking is making mainstream products and services more accessible for mainstream users and those with specific requirements, without making special adaptations. This indicates that the UD product market based on the "respect each individual to achieve self-actualization" ideal is rapidly growing [1]. User requirements, market knowledge, and approaches that are easy to understand are used to design and produce products that can achieve maximal usability for individual users [2]. As the global aging problem has become increasingly concerning, universal design (UD) has become the current trend of design development in various fields. UD involves the creation of a tolerant and sustainable society in which everyone can participate and people with different abilities, limitations, and needs can use products equally and conveniently, which directly and indirectly benefits the society [3]. Therefore, UD application methods for product development are an urgent problem because of the constantly increasing demand for UDs in societies and industries. Numerous companies have implemented UD and raised product design and development requirements. For example, Mitsubishi Electric built a UD evaluation tool, UD-checker, to evaluate the universality of the product categories that are designed and produced by the company [4]. In addition, Panasonic developed six UD guidelines covering operations, space, usage, and maintenance of its products [5]. Although UD is often a crucial part of product evaluation before application, it is mostly used for post 
hoc evaluation at the end of product development, which results in UDs often being reflected in additional features [6,7]. The effects are notable when interventions occur in the early stages of product development [8], such as during product-demand strategy and product-specification planning. These results help designers to create systematic designs for efficient and accurate product development [9]. Lin and $\mathrm{Wu}$ [2] used needle-nose pliers as an example by introducing UD concepts at the early design stage and discussing the universality and uniqueness of UD scales (i.e., extensive UD scales often lack the relevance to clearly guide product development). Although product development often involves a concept-evaluation-development-test-release process, targeted adjustment is performed in the actual process because of the differences among product types [10]. Therefore, the process and method of UD introduction must be treated differently according to the differences among product-development types. Studies have proposed corresponding development models with product types. Henderson and Clark divided product-development models from design factors: incremental, architectural, modular, and radical [11]. Demirbilek [12], Shraddha [8], Lin \& Wu [2], and Wu [13] have conducted UD studies on specific groups and product characteristics from different perspectives by using user groups and product characteristics. The UD scale must be adjusted according to product differences in order to determine the scope and rules of its application. Among the four product-development models, architectural innovation refers to maintaining core design concepts (including a basic knowledge of components) and changing the approaches in order to connect product components for application breakthroughs in architecture, while retaining the original function implementation. Different design factors are presented when the core design concepts and functions of products are realized [11]. However, current methods cannot effectively match UD principles and product design factors because of the diversity and differences in product design factors. For instance, the function of umbrella stands can be achieved through design factors, such as the implementation of a bucket container or hook, but corresponding it to the same UD principle is difficult. Consequently, the evaluation criteria of designers and users are inconsistent, and users' needs cannot be realized during the design stage. Hence, studies are required on the methods of introducing UD into architecturally innovative products.

Umbrella stands are a commonly used product with a clear function. However, various styles of umbrella stands that are currently on the market display nonspecific design factors that can easily lead to confusion in their evaluation and recognition, and they are regarded as typical architecturally innovative products. Therefore, an architectural product-development process was constructed from the UD product-development model in order to verify the methodology extension.

This study explored UD application during the design process of architecturally innovative products, mainly with the following three purposes:

(1) To explore the development and application of appropriate UD scales for different products.

(2) To discuss the diversification of architecturally innovative products and how inexact design factors are summarized and ranked by importance.

(3) To develop a proper UD-introduction procedure and implement user verification of two umbrella-stand designs.

\section{Research Objectives and Processes}

The broader meaning of universality implies that targeted adjustments must be made to the evaluation target during its application. Moreover, the differences among product types determine the appropriate considerations and design methods that are required for UD introduction. This study investigated how to integrate, screen, and rank the design factors of an architecturally innovative product when UD is introduced, and how to assist in product-development completion on the basis of its importance during UD evaluation. 


\subsection{Appropriate Adjustment of Universal-Design Scale to Product Type}

Products demand change, and UD principles are constantly being improved and enriched. From an initial focus on accessibility to the gradual consideration of the widest user groups [14-16], the Japanese Ergonomics Society later incorporated fairness as the basic principle for summarizing the three aspects of product evaluation: operability, usefulness, and charm [17]. Since the emergence of interaction design, the usability principle has gradually been incorporated into UD considerations. Flexibility and error tolerance are closely related to the ease of use of products [18]. Optimizing product usability can maximize product satisfaction [19]. Therefore, usability is a crucial indicator when evaluating product universality. As research participants of this study, users of umbrella stands and diversified visual attributes were used, along with usability principles, to enhance UD-scale design [20]. The development and enhancement of the UD scale revealed that UD remains an underdeveloped design concept and method. The effective application of concepts for practical applications and to introduce design and usability principles into design and development were critical research objectives of this study.

\subsection{Characteristics of Architectural Innovative Products}

Architecturally innovative products should alter product-component-arrangement methods while maintaining core design concepts and working principles [11]. Product architecture is a key concept of product innovation, and architecture is a design pattern that functionally expresses design factors [21]. Ulrich proposed a three-phase procedure for product implementation according to the product concept: (1) decide the product functions, (2) decide the design-factor levels as functions, and (3) determine the design factors [22]. Although performance results in the same function, various morphological differences occur. Moreover, understanding product characteristics in the early design stages can help designers make satisfactory decisions [23]. Many daily necessities have the characteristics of clear functions but diversified structure and design elements. For example, umbrella stands functioning as umbrella storage is extremely clear, but the styles (e.g., hanging and bucket) of umbrella stands on the market considerably differ [24]. These kinds of products would be frequently used in daily life and would have to meet the needs of the users of different genders and ages and be used in different scenarios. So, the universal design of such products is very important. Because of its clear functions and design factors, umbrella stands can be used to explore the UD product-development model in architecturally innovative product types in order to substantially improve the development process of such innovative products and enhance their universal value.

\subsection{Process and Verification of Introducing Universal Designs into Architecturally Innovative Product Types}

The industry has agreed that UD principles cannot be used only for ex-post evaluations. Afacan, Erbug [14] and Bjork [25] have proposed principles for UD. Demirbilek [12] proposed a participatory design model for related product design that fully meets user demands through participatory meetings. Kostovich [26] suggested improving UD research and practice through action-function diagrams. Moreover, Otto, Wood [27] and Hirtz [28] integrated action-function diagrams and functional models in order to illustrate the differences between universal and nonuniversal products. Such formal user product representation is useful for comparing typical and universal products and the related data mining and collection [23]. Studies have attempted to clarify product functions by exploring and converting user needs into essential UD references. The limitations were identified, and the complexity of the design factors for architecturally innovative product types could not be fully represented through action-function diagrams during integration [23].

When introducing UD into different types of products, appropriate adjustments must be made according to the product characteristics. Providing a systematic evaluation framework for products by using a broad UD scale is difficult [19,29]. Wu [13] used screwdrivers as an example of guiding the completion of universal product development 
from importance rankings by converting user evaluations into design factors. However, screwdrivers lack universality because of their fixed design factors. For architecturally innovative products, inexact design factors and methods of constructing reasonable and scientific models must be explored. By converting previous user experiences or evaluations into design factors for integration and screening, an effective set of UD-introduction models can be developed in order to provide a reference for product design and development.

\section{Research Methods and Experimental Procedures}

This study explored the deduction of architecturally innovative product types in UD product design and development models. This study raised the following hypothesis: the new UD-importation process and method can significantly improve the UD evaluation of architecturally innovative product development. This study used umbrella stands with unclear design factors as an example, introduced UD principles into the development process, and performed design verification (Figure 1). The specific steps were divided into three parts: (1) integrate the UD principles of umbrella stands by combining current UD principles, usability principles, and user experience interviews; (2) select representative experimental samples through cluster analysis in order to define the design factors of umbrella stands according to user evaluations and usage habits; and (3) quantitatively classify the importance of umbrella-stand design factors using Quantitative Theory Type I in order to design a universal umbrella stand, compare the differences between the new and old umbrella stands during UD evaluation, and verify the effectiveness of this design process for implementing architecturally innovative products.

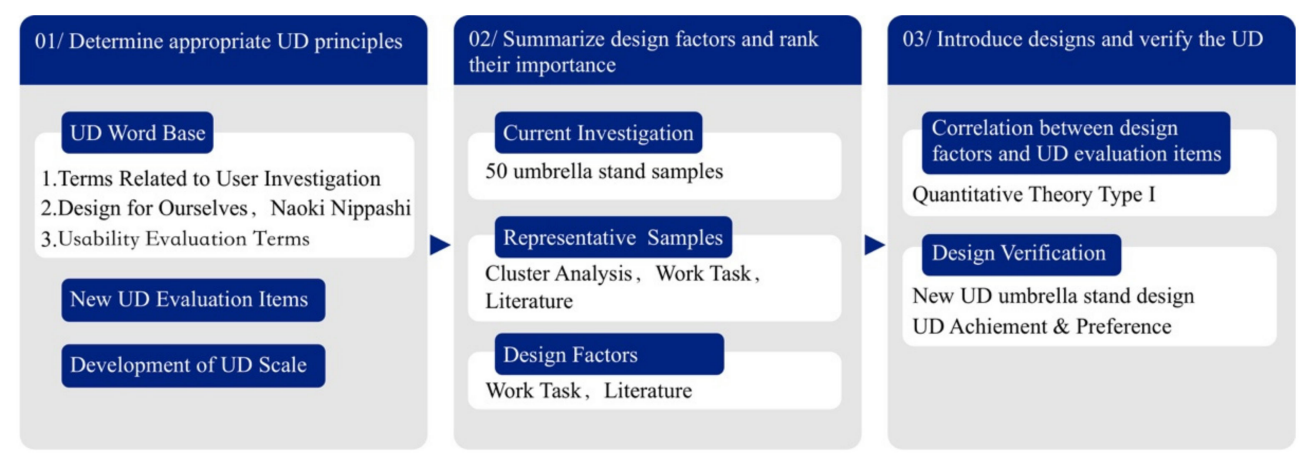

Figure 1. Research methods and experimental procedures.

\subsection{Experiment 1 (Universal-Design Scale for Umbrella Stands)}

The objective of this experiment was to obtain an appropriate UD scale for umbrella stands, which have unclear design factors. First, a qualitative interview on umbrella-stand usage was conducted. From the satisfaction survey, the terms related to the evaluation of umbrella-stand usage in the interview results and the questionnaire were extracted. Second, 71 UD terms from the "design for yourself" concept proposed by Nippashi [30] and 73 usability evaluation terms converted by Hoehle [31] were integrated. In order to avoid a misunderstanding among participants, which could affect the evaluation, the overspecialized and technical terms were deleted and terms with similar meanings were merged after consulting with experts in related fields. These terms were transformed into more understandable evaluation items based on the operating behavior of umbrella stands in order to obtain the initial UD scale. However, UD is a broad design concept with some design vocabulary and evaluation items that are inapplicable to umbrella stands. In order to avoid ambiguity in meaning, this study asked participants to rate the relevance of the initial UD scale through a correlation survey and to delete the items with low relevance and ambiguous semantics. The principal component analysis for factor analysis was adopted, and the scale reliability was detected through reliability analysis. Finally, the final UD scale for umbrella stands was determined. The number of participants tested at this stage was comprised of 83 people: 41 men and 42 women. A total of 18,16,14,14,12, and 
18 participants were aged in their 10s, 20s, 30s, 40s, 50s, and 60s, respectively. To ensure that this experiment fully reflected the spirit of UD, the standards in the first stage were used for participant selection.

\subsection{Experiment 2 (Selection of Representative Experimental Samples and Design Factor Definition)}

The objective of this experiment was to clarify umbrella-stand design factors by classifying, screening, and defining them. The diverse user group of umbrella stands results in inconsistent product expectations (e.g., the user and maintainer roles and the usage habits of long or folding umbrellas), and these differences are reflected in the design factors and functions of umbrella-stand products [32]. The number of participants in this experiment was 61, with 30 men and 31 women. In total, 12, 11, 9, 9, 10, and 10 participants were aged in their 10s, 20s, 30s, 40s, 50s, and 60s, respectively. Wide age distributions ensure the importance of the individual and fairness in society. Therefore, this study selected participants with different ages, genders, roles, and habits of using umbrellas, which fully reflected the spirit of UD.

Due to the large differences in umbrella-stand design, the differences in characteristics such as appearance, product materials, and operation methods must be fully considered when selecting experimental samples. A wide range of 50 commercially available umbrellastand samples is displayed in Figure 2. However, the samples were grouped because large sample sizes can affect the mental load of the participants. The participants were required to complete a questionnaire based on their personal experience after completing the umbrella-stand-operation task. The use of umbrella stands is simple because of their clear and specific functions, and the operation process was divided into three steps: "place the umbrella," "position the umbrella," and "take the umbrella." Subsequently, a 5-point Likert scale was used for evaluation. The design factor items were sorted in order to facilitate the participants' accurate expression of feelings and opinions when evaluating the umbrella stands. Finally, a representative experimental sample was obtained through cluster analysis. Moreover, the design factors of the umbrella stands were defined through the steps from the literature.

By combining the user behavior and the interviews with the representative characteristics of samples, this study defined seven design factors of umbrella stands regarding appearance, usage method, and architectural characteristics and numbered each design factor (classification level) in order to facilitate the next stage of quantitative statistics using Quantitative Theory Type I (Table 1).

Table 1. Summary of umbrella-stand design factors.

\begin{tabular}{ccccc}
\hline $\begin{array}{l}\text { Umbrella Stand } \\
\text { Design Factors }\end{array}$ & Level 1 & Level 2 & Level 3 & Level 4 \\
\hline Water collector & Form & Merged & Separation & - \\
\hline \multirow{2}{*}{ Putting umbrella } & Hole of umbrella & Yes & No & - \\
& Quantity & $5-8$ & $9-12$ & $13-16$ \\
\hline \multirow{2}{*}{ Whole } & Material & Rubber & Plastic & Metal \\
& Style & Geometric & Organic & - \\
\hline Operation & Structure & Line & Plane & Solid \\
\hline
\end{tabular}




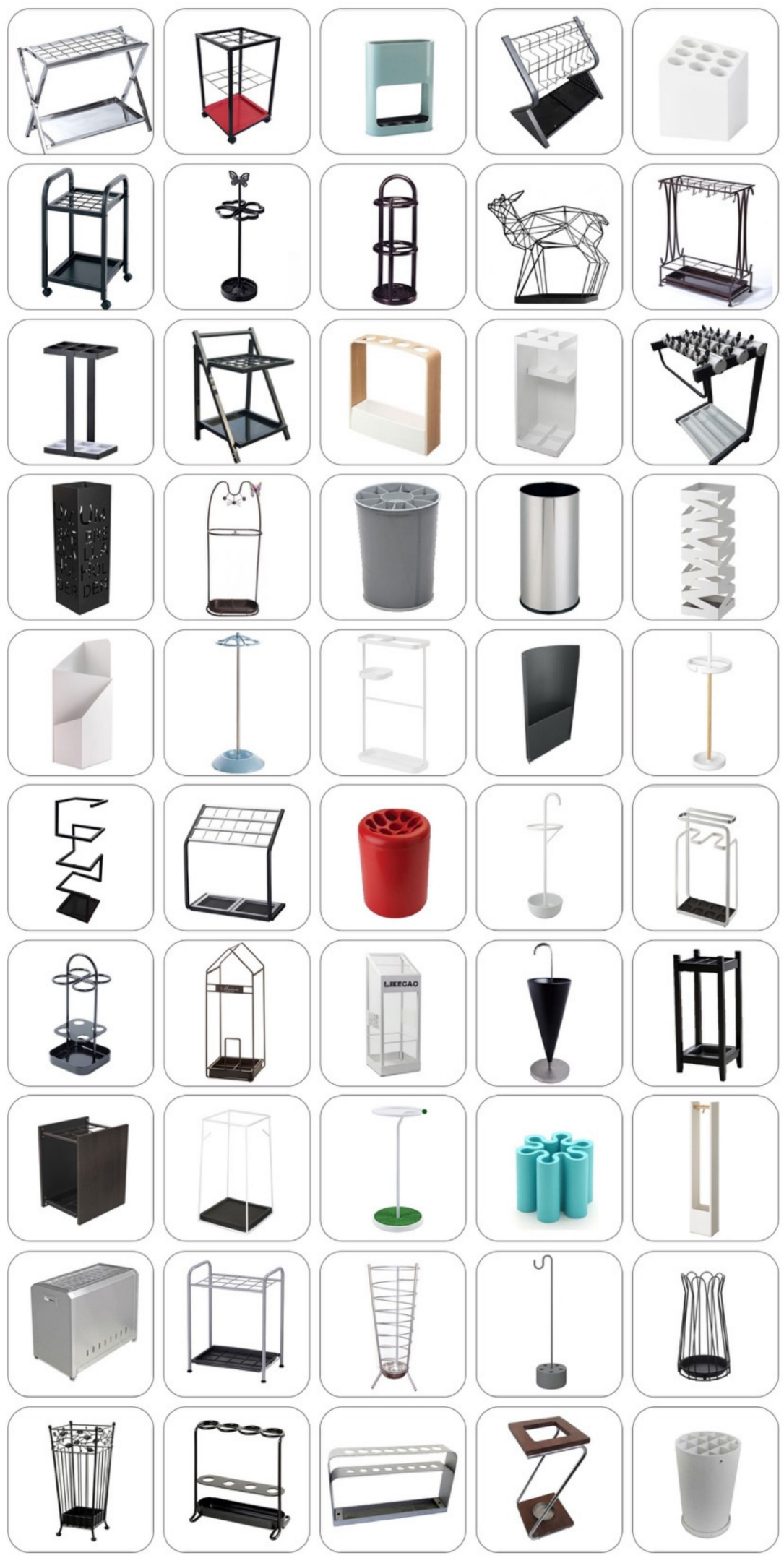

Figure 2. Collection of commercially available umbrella-stand types. 


\subsection{Experiment 3 (Introducing Universal Design into Product Development for Verification)}

UD was introduced into the architecturally innovative product-development process for verification. The umbrella-stand design factors and UD scale that were obtained in previous experiments were ranked by importance using Quantitative Theory Type I in order to obtain a crucial reference basis for the UD of umbrella stands. Accordingly, two new UD umbrella stands were completed, and the UD scale was used again to evaluate the correctness and feasibility of the design method and whether the practical applications were improved. The number of participants tested at this stage was 42 , with 22 male and 20 female participants. In total, 5, 7, 9, 8, and 8 participants were aged in their 10s, 20s, $30 \mathrm{~s}, 40 \mathrm{~s}, 50 \mathrm{~s}$ and $60 \mathrm{~s}$, respectively. The same operational tasks and questionnaires as in Experiment 1 were used to judge the UD performance of the newly designed umbrella stands in order to obtain the most effective results.

\section{Results}

This study used umbrella stands as the target product for exploring the universality and uniqueness of the current UD scale and principles, and it analyzed the effects of their application on architecturally innovative product types. The possible factors causing the differences were investigated in order to verify the deduction of this evaluation methodology through design.

\subsection{Changes in Universal-Design Principles According to Product Characteristics}

The UD umbrella-stand evaluation items were extracted by principal component analysis and reranked according to their weighted importance in order to form a new component dimension and determine its importance [33]. In order to evaluate the convergent validity of each dimension on the scale, a factor load of 0.5 was used $[34,35]$, and the cases where the absolute value of the factor load was more than 0.5 in two or more dimensions were excluded in order to review the scale's discriminative validity for verifying the construct validity of the UD umbrella-stand scale. In addition, the Cronbach's $\alpha$ coefficient value of the reliability analysis was used as a standard for judging the internal consistency of the scale dimensions. The results revealed that the reliability of the questionnaire was 0.960 , which indicated that this scale was highly accurate because the benchmark reliability coefficient value of excellency was set at 0.7 [36]. Therefore, the seven UD principles of universal umbrella-stand designs were obtained and named according to the evaluated items and their meanings. The seven UD principles of umbrella stands proposed by this study were ranked in descending order in terms of their importance and degree of influence, which were based on the considerations of the individual and the societal level that the product design had taken and the effects of familiarity of usage on the product usability. Specifically, the descending order ranking was P5 combined types of products (0.947), P6 cost considerations of products (0.947), P7 familiar use effects of products (0.946), P1 social aspects and functions of products (0.863), P4 added value of products (0.788), P2 usability of products $(0.686)$, and P3 appearance characteristics of products (0.633); a total of 36 items were evaluated (Table 2). According to the reliability and validity indicators from the scale, the reliability of P1, P4, P5, P6, and P7 were all >0.7, and the reliability of P2 was 0.686 (close to 0.7 ). The details examined covered product safety, product operability, and product use requirements. The compositional differences of these items led to deviations in the participants' evaluation. The reliability of P3 was 0.633 , which covered a wide range of factors including the appearance of attractiveness, material performance, and whether the form corresponded to function. Diversified factors also affected the participants' evaluation. The results indicated that 36 evaluation items and 7 principles exhibited a certain reliability and validity, which indicated that this UD scale was suitable for umbrella-stand evaluation. 
Table 2. Comparison and difference with UD principles.

\begin{tabular}{|c|c|c|}
\hline CUD and Mace's 3B Principles & Satoshi Nakagawa [37] & The UD Principles Proposed in This Study \\
\hline Equitable use & Anyone can use the product equitably & $\begin{array}{l}\text { Product consideration for individuals and society } \\
\text { (Subitem 1) Communication of social and cultural values } \\
\text { (Subitem 2) Product usage feedback } \\
\text { (Subitem 3) Product attractiveness } \\
\text { (Subitem 4) Adjustability }\end{array}$ \\
\hline Flexibility in use & Enable use through various methods & $\begin{array}{c}\text { Product usability } \\
\text { (Subitem 1) Safety considerations } \\
\text { (Subitem 2) Operability } \\
\text { (Subitem 3) User demand satisfaction }\end{array}$ \\
\hline Simple and intuitive use & Use is simple and easy to understand & Product appearance characteristics \\
\hline Perceptible information & $\begin{array}{l}\text { Can use multiple sensual organs to } \\
\text { understand message }\end{array}$ & Product added value \\
\hline Tolerance for error & $\begin{array}{l}\text { Improper use of the product will not cause } \\
\text { accidents, and the product can be returned to } \\
\text { its original shape }\end{array}$ & Combinations \\
\hline Low physical effort & Reduce physical burden on users & Costs \\
\hline Size and space for use & Ensure convenient size and space for use & Familiarity \\
\hline Optimal design & $\begin{array}{c}\text { Supplement } 1 \\
\text { Durability and economics }\end{array}$ & - \\
\hline Beauty & $\begin{array}{c}\text { Supplement } 2 \\
\text { Quality and aesthetics }\end{array}$ & - \\
\hline Good business & $\begin{array}{c}\text { Supplement } 3 \\
\text { Health and environment }\end{array}$ & - \\
\hline
\end{tabular}

The UD evaluation principles proposed by the Center for Universal Design, College of Design, North Carolina State University (CUD) and Nakagawa [37] are widely applied. Therefore, the principles from CUD and Nakagawa [37] are compared in Table 2. The seven UD principles proposed by this study resemble the UD principles proposed by CUD and Nakagawa. For example, the first principle focuses on personal and social values, which are essentially consistent with the previous connotation of equitable and flexible use. This indicated that the primary goal of UD is to ensure equitable use among people and society, which reflects tolerance. The usability principle is more crucial than the previous UD scale. According to usability and user experience perspectives, whether this principle has satisfactory usability is the focus of the users' attention, particularly as a daily product. Therefore, the UD scale was gradually enhanced and developed over time. For the third principle, product appearance characteristics suggest that the importance of specific products varies across product types or characteristics. The first three UD principles of umbrella stands presented a cumulative explanatory power of $>50 \%$, which was the focus of the UD principles for umbrella stands. The product-added-value principle was consistent with some of the connotations of the perceptible-information principle. The usability principle was classified as ease of operation, which is an original UD principle. Such differences in details can be attributed to differences in item design and user perception. Often a single principle may involve more than one design concept because the original UD principle has wide coverage.

According to relevant studies, UD evaluation principles may lead to varying evaluation results because of differences in product characteristics and categories, and the effects of each principle are different [38]. Therefore, this study compared the UD principles of consumer products [38], needle-nose pliers [2], and screwdrivers [13] in Table 3. 
Table 3. Comparison and difference with UD principles.

\begin{tabular}{|c|c|c|c|}
\hline $\begin{array}{l}\text { UD Principles for Consumer } \\
\text { Products [38] }\end{array}$ & $\begin{array}{c}\text { UD Principles for } \\
\text { Needle-Nose Pliers [2] }\end{array}$ & $\begin{array}{l}\text { UD Principles for } \\
\text { Screwdrivers [13] }\end{array}$ & $\begin{array}{l}\text { UD Principles Proposed } \\
\text { in This Study }\end{array}$ \\
\hline Energy conservation & $\begin{array}{l}\text { User functional requirement } \\
\text { satisfaction } \\
\text { (product-design } \\
\text { characteristics) }\end{array}$ & Fairness and functionality & $\begin{array}{c}\text { Product consideration for } \\
\text { individuals and society } \\
\text { (Subitem 1) Social and cultural } \\
\text { value communication } \\
\text { (Subitem 2) Product usage } \\
\text { feedback } \\
\text { (Subitem 3) Product } \\
\text { attractiveness } \\
\text { (Subitem 4) Adjustability }\end{array}$ \\
\hline Susceptibility & $\begin{array}{l}\text { Psychological, spiritual, and } \\
\text { social user self-actualization } \\
\text { needs }\end{array}$ & $\begin{array}{c}\text { Information perception and } \\
\text { usability } \\
\text { (product-design } \\
\text { characteristics) }\end{array}$ & $\begin{array}{c}\text { Product usability } \\
\text { (Subitem 1) Safety } \\
\text { considerations } \\
\text { (Subitem 2) Operability } \\
\text { (Subitem 3) User demand } \\
\text { satisfaction }\end{array}$ \\
\hline Flexibility & Commercial value & $\begin{array}{l}\text { Experience and commercial } \\
\text { value }\end{array}$ & $\begin{array}{l}\text { Product-appearance } \\
\text { characteristics }\end{array}$ \\
\hline Adjustability & Task completion degree & $\begin{array}{c}\text { Durability and economic } \\
\text { efficiency }\end{array}$ & Product added value \\
\hline Intuition and usability & $\begin{array}{l}\text { Space and environmental } \\
\text { considerations }\end{array}$ & Ease of operation & Combinations \\
\hline Accessibility & Tolerance & Adjustability & Costs \\
\hline Ease of operation & Adjustability & Tolerance & Familiarity \\
\hline Fairness & - & - & - \\
\hline Safety & - & - & - \\
\hline Tolerance & - & - & - \\
\hline Product size & - & - & - \\
\hline
\end{tabular}

The first principle compared involved the personal and social values of fairness and functionality from $\mathrm{Wu}$ [13] to meet users' functional, psychological, and self-fulfillment needs [2] and the fairness and adjustability of consumer products [38]. All of these reflected a consistent general meaning. This showed that the basic fairness and tolerance of these principles were one of the most influential factors among the products. However, items for umbrella stands focused more on their social role than those of consumer products and hand tools because umbrella stands are mostly used in public places. The second principle of product usability was similar to the previously proposed principles regarding safety considerations, operability, and usage demands. Whether a specific product can be used reasonably is a critical consideration. The third principle of product appearance characteristics was less essential than the other principles. However, it reflected the product type differences in UD principles. As an architecturally innovative product, umbrella stands can have rich and diverse design factors, even with a clear function. Changes in product appearance are inevitable because design-factor diversification is presented through various materials, colors, processes, and styles [39]. These appearance differences have become the focus of consumer evaluations of products. In addition, these complexities cause great difficulties for designers in determining design directions in the early stages. Choosing practical design factors to complete product designs is critical. Therefore, combining design factors with UD principles for screening and ranking is a key step for introducing UD in architecturally innovative products. A screwdriver's appearance focuses more on the semantic expression of functional operation than on product design 
characteristics [13], and the appearance of umbrella stands mainly concerns their style and visual appeal as daily consumer products.

Combinations appeared as independent principles in this study mainly because umbrella use can be differentiated between long and short umbrellas, and role differences among users and maintainers caused users to pay more attention to the combinations (e.g., cleaning and maintenance of umbrella stands), which reflected the focus of all users on the UD principles. Significant differences in product design factors inevitably result in large differences in product cost, which is an essential consideration factor for users. Moreover, due to the diversification of design factors, differences in product style and form affect users' familiarity with product operations.

Therefore, scale designs should vary when UD principles and scales encounter different product category evaluations; otherwise, potential design factors may be neglected because of differences between the evaluated items. The evaluation principles and items were different even for similar products, and the importance ranking of the design principles indicated such differences. For architecturally innovative products, product appearance characteristics and cost considerations were typical UD principles. This also highlighted the operating importance of integrating and screening the design factors for products in the UD process.

\subsection{Summary and Importance Ranking of Umbrella-Stand Design Factors}

Cluster analysis was applied in order to obtain representative test samples, and 50 umbrella stands with different styles on the market were collected in order to maximize the design information. The umbrella stands were divided into seven clusters according to the cluster analysis tree diagram, and a representative experimental sample was selected from each cluster (see Figure 3). These samples essentially covered most umbrella-stand products on the market. Although the function of these umbrella stands is to store umbrellas, their types varied from bucket, hanging, lattice, and line designs. These inexact design factors directly added complexity to the products' appearances [23], which resulted in the slowed focus of designers during the initial design development. Therefore, this study focused on obtaining the optimal combination that meets UD principles through cluster analysis and the employment of Quantitative Theory Type I to screen and rank the design factors.
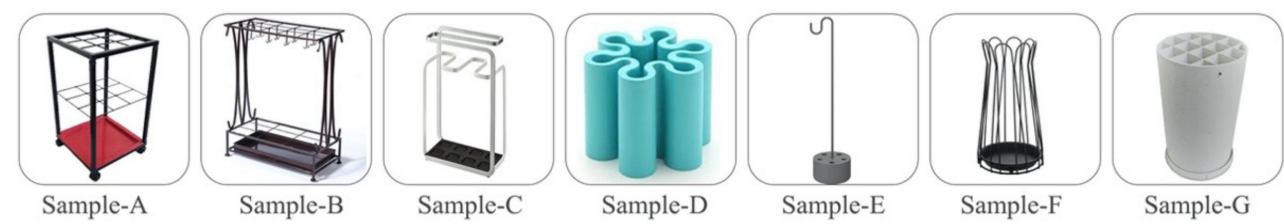

Figure 3. Representative experimental samples.

According to the UD umbrella-stand-evaluation scale proposed by this study, umbrellastand design factors were quantified through Quantitative Theory Type I, which identifies the correlation between design factors and evaluation items. The relevance and degree of importance were examined according to the partial correlation coefficients, and design factor types were determined from the type scores. Users' UD perspectives were directly transformed into universal umbrella-stand design factors, which provided designers or manufacturers with suggestions and considerations for the future. According to Table 4, the results of the partial correlation coefficients indicated that the overall structure (0.832) was the main factor affecting the design of the universal umbrella stand, and the line structure (0.343) was obtained through the type scores. The advantage of this is that users can clearly see the whole umbrella stand, which allows users to feel that the umbrella is not stuffy and difficult to clean, and the line structure makes the whole stand lightweight and achieves environmental-protection and material-saving purposes. The overall material was the second factor (0.831). Metal material (0.337) obtained through type scores was 
the first choice of umbrella-stand material because of its stable and durable characteristics. Subsequently, the factor that affected universal umbrella-stand design was the number of umbrellas that umbrella stands could fit (0.816), and the most desired design for users allowed for 13-16 umbrellas (0.386). For umbrella-stand products, one of the most concerning problems was the umbrella-placement space, which corresponded to the number of umbrellas that can be placed in the design factors. The findings revealed that the design can be performed for integrated and converged design factors with a high degree of UD achievement.

Table 4. Partial correlation coefficient of UD evaluation.

\begin{tabular}{|c|c|c|c|c|}
\hline $\begin{array}{l}\text { Umbrella Stand } \\
\text { Design Factors }\end{array}$ & Type & Type Scores & \multicolumn{2}{|c|}{ Partial Correlation Coefficient } \\
\hline Water Collector & Form & $\begin{array}{c}\text { Merged } \\
\text { Separation }\end{array}$ & $\begin{array}{c}-0.430 \\
0.323\end{array}$ & 0.781 \\
\hline \multirow{2}{*}{$\begin{array}{l}\text { Putting } \\
\text { Umbrella }\end{array}$} & $\begin{array}{c}\text { Hole of } \\
\text { Umbrella }\end{array}$ & $\begin{array}{l}\text { Yes } \\
\text { No }\end{array}$ & $\begin{array}{c}-0.063 \\
0.157\end{array}$ & 0.344 \\
\hline & Quantity & $\begin{array}{c}5-8 \\
9-12 \\
13-16\end{array}$ & $\begin{array}{c}-0.441 \\
0.275 \\
0.386\end{array}$ & 0.816 \\
\hline \multirow{3}{*}{ Whole } & Material & $\begin{array}{c}\text { Rubber } \\
\text { Plastic } \\
\text { Metal }\end{array}$ & $\begin{array}{c}-0.597 \\
-0.155 \\
0.337\end{array}$ & 0.831 \\
\hline & Style & $\begin{array}{c}\text { Geometric } \\
\text { Organic }\end{array}$ & $\begin{array}{c}0.014 \\
-0.019\end{array}$ & 0.059 \\
\hline & Structure & $\begin{array}{l}\text { Line } \\
\text { Plane } \\
\text { Solid }\end{array}$ & $\begin{array}{c}0.343 \\
-0.485 \\
-0.403\end{array}$ & 0.832 \\
\hline Operation & Method & $\begin{array}{c}\text { Insert } \\
\text { Insert \& Put }\end{array}$ & $\begin{array}{c}-0.135 \\
0.101\end{array}$ & 0.245 \\
\hline
\end{tabular}

\subsection{Design Verification}

Two umbrella-stand designs were completed based on the universal umbrella-stand design factors that were summarized in related studies, both of which were based on a line structure in order to allow users to clearly see the whole stand and not feel that the umbrella stand was stuffy or difficult to clean. Moreover, the line structure made the entire stand lightweight in order to achieve environmental-protection and material-saving purposes. In addition, metal materials were used to construct the umbrella stand in order to ensure the structure stability and product durability. Another style of umbrella stand used a hexagonal extension shape to utilize the space. Both styles were designed with an internal and external double-layered structure in order to separate long and short umbrellas. Each could accommodate 16 umbrellas, and the final design is presented in Figure 4.

The verification results revealed that the scores of universal umbrella-stand designs improved significantly in various areas. The measurement effect of both umbrella stands had higher scores in indicative primary principles than did the representative samples that were selected from the market, which indicated that the redesign of umbrella stands after analysis and induction could effectively improve the UD and product usability. 


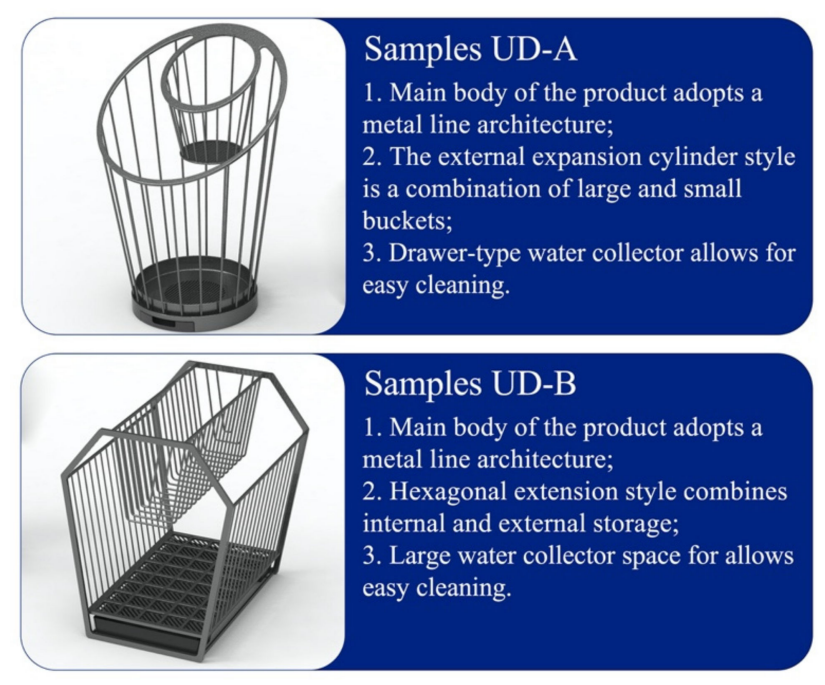

Figure 4. UD umbrella-stand designs.

This study used the one-way analysis of variance to clearly determine the differences between conventional and UD umbrella stands and examine whether significant score differences occurred between newly designed umbrella stands and conventional umbrella stands by using the seven UD principles. Subsequently, the Bonferroni analysis was used to compare the score differences between umbrella-stand samples. The results indicated that the overall score of UD umbrella stands could be improved by corresponding them to the principal components and solving the problems raised by users in surveys. The principles of product consideration by individuals and society, product usability, product appearance characteristics, product added value, comprehensive evaluation of degree of preference, universal completion degree, and satisfaction were significantly more satisfactory in the UD umbrella stands than in the umbrella stands from the original representative samples, which are displayed in the radar chart (Figure 5). The findings revealed that the UD umbrella stands were better than the commercially available umbrella stands on the market. The UD umbrella stands used a cylinder and a hexagon as their main extension styles, which allowed for a more efficient use of space, more differentiated space between long and short umbrellas, and higher water-collection capacity. Redesigning array line structure styles could unify the products, which effectively improved the general satisfaction of umbrella stands according to the design optimization conditions. For the product costs, no significant difference in the one-way analysis of variance was noted $(p=0.192>0.05)$, which implied that no significant difference occurred in "component 6 " between the umbrella stands. The main factor was that the prices of each umbrella stand were not labeled, and users could only judge umbrella stand costs among materials and styles based on their experience. Moreover, the design verification models in this study are not mass-produced, which makes it difficult for users to compare them with the currently available umbrella stands, which in turn resulted in no compositional difference.

Users of all ages were targeted in this experiment and they evaluated several aspects, including usage, maintenance, cleaning, and indoor and outdoor use. However, the actual use of wet umbrellas outdoors is difficult to be taken into consideration. The new UD evaluation method of this study continued the original UD keyword search conversion, performed the item analysis and principal component analysis screening, and used Hayashi's quantification method I to clearly correspond to design factors, which were applied in product development. 


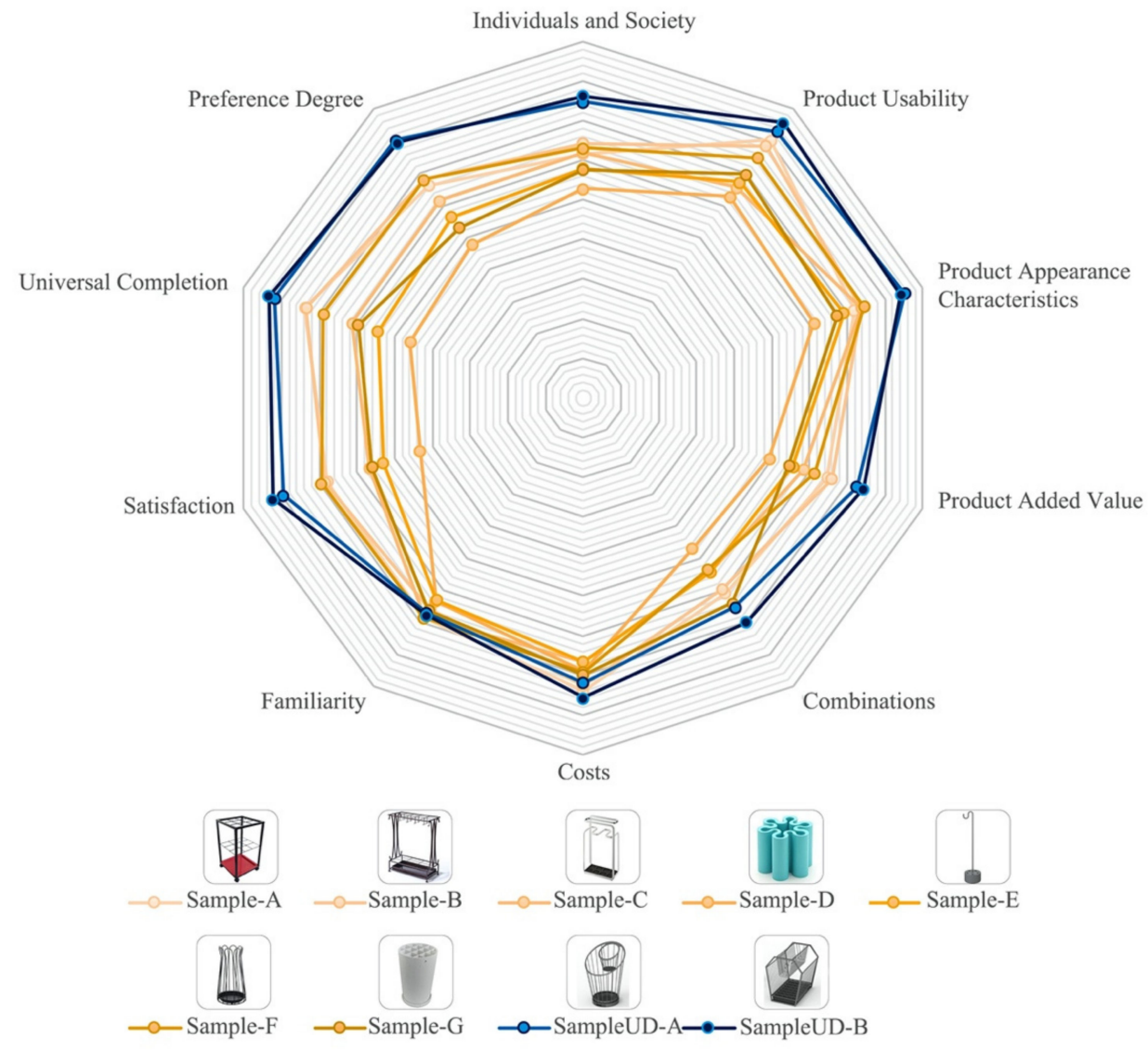

Figure 5. UD achievement of design verification.

\section{Conclusions and Recommendations}

During the introduction of UD into product development, overly extensive scales lack effective targeting and are unable to provide practical help for product design and development or valuable references. To conform to the spirit of UD, the UD scale must be adjusted by the product category and the characteristics. Although the architecturally innovative product function was clear in this study, the inexact design factors caused ineffective responses and evaluation when introducing UD.

This study used umbrella stands as research objects for constructing UD principles and evaluation scales according to the product categories. The findings revealed that the current UD principles exhibited universality, but certain principles and evaluation items still varied by the evaluated objects (i.e., focus of attention among professional tools and daily necessities were significantly different). Some evaluation items were highly related to the product characteristics, such as the style and usage method, the coordination of materials, and the aesthetic appearance. The inexact design factors for umbrella stands reflected the diversified styles and product characteristics. A review of different product categories and current universal UD principles revealed the universality of the UD principles and scales that were discussed in this study, although the uniqueness of the evaluated objects should still be considered. In addition, designers can effectively draft solutions for design development based on the evaluation tools by considering the users' and designers' perspectives in the initial stage. Specifically, they can construct a linkage between the product-design characteristics and the UD concepts with clear translations of users' UD evaluations into design guidelines that the designers can understand. Furthermore, in coordination with the UD principles of umbrella stands, inexact design factors can be ranked and screened from sufficient samples in order to select optimal combinations as references for UD umbrella stands (e.g., metal material, number of umbrellas between 13 and 16, and line structure). Finally, the effectiveness and deduction of this method 
were confirmed through design verification. Future studies can investigate other types of product innovation models and determine the appropriate user groups to achieve the UD spirit and be applicable to the majority of users.

Author Contributions: C.G.; writing—original draft preparation, K.-C.L.; supervision, project administration, Z.-Y.W.; data analysis, investigation. All authors have read and agreed to the published version of the manuscript.

Funding: This research received no external funding.

Institutional Review Board Statement: Not applicable.

Informed Consent Statement: Not applicable.

Data Availability Statement: Not applicable.

Acknowledgments: Thanks to Chih-Fu Wu for his advice and guidance.

Conflicts of Interest: The authors declare no conflict of interest.

\section{References}

1. Keates, S.; Clarkson, J. Countering Design Exclusion; Springer: London, UK, 2004.

2. Lin, K.C.; Wu, C.F. Practicing universal design to actual hand tool design process. Appl. Ergon. 2015, 50, 8-18. [CrossRef] [PubMed]

3. Ostroff, E.; Preiser, W. Universal Design Handbook; MacGraw Hill: Boston, MA, USA, 2001.

4. Sawada, K.; Fukano, S.; Sakayori, E.; Kosaka, M. Creation of a tool for universal design development evaluation UD-checker creation and examples of use. In Proceedings of the 2nd International Conference for Universal Design in Kyoto, Kyoto, Japan, 22-26 October 2006.

5. Panasonic. Available online: http://www.panasonic.net/center/tokyo/floor/floor_03/index.html (accessed on 8 March 2010).

6. Liu, Y.E.; Lee, S.T.; Kascak, L.R.; Sanford, J.A. The Bridge Connecting Theory to Practice-A Case Study of Universal Design Process. In Proceedings of the International Conference on Universal Access in Human-Computer Interaction, Los Angeles, CA, USA, 2-7 August 2015; pp. 64-73. [CrossRef]

7. Newell, A.F.; Gregor, P. “User sensitive inclusive design" - In search of a new paradigm. In Proceedings of the 2000 Conference on Universal Usability, Arlington, VA, USA, 16-17 November 2000; pp. 39-44. [CrossRef]

8. Sangelkar, S.; Cowen, N.; Mcadams, D. User activity—Product function association based design rules for universal products. Des. Stud. 2012, 33, 85-110. [CrossRef]

9. Gual, J.; Lloveras, J.; Puyuelo, M.; Romero, F. A proposal of an evaluation model under the principles of universal design. In Proceedings of the International Design Conference-Design 2010, Dubrovnik, Croatia, 17-20 May 2010.

10. Booz; Allen; Hamilton. New Products Management for the 1980s; Allen \& Hamilton: New York, NY, USA, 1982.

11. Henderson, R.M.; Clark, K.B. Architectural innovation: The reconfiguration of existing product technologies and the failure of established firms. Adm. Sci. Q. 1990, 9-30. [CrossRef]

12. Demirbileka, O.; Demirkanb, H. Universal product design involving elderly users: A participatory design model. Appl. Ergon. 2004, 35, 361-370. [CrossRef]

13. Wu, C.F.; Lin, K.C.; Yang, C.Y.; Liao, S.F. The influence of relationship between distinct hand tools and universal design scales with screwdriver. J. Des. 2016, 21, 25-34.

14. Afacan, Y.; Erbug, C. An interdisciplinary heuristic evaluation method for universal building design. Appl. Ergon. 2009, 40, 731-744. [CrossRef]

15. Kawauchi, Y. Universal Design—Questions for Barrier Free; Gakugei Publishing: Kyoto, Japan, 2001.

16. Bendixen, K.; Benktzon, M. Design for All in Scandinavia-A strong concept. Appl. Ergon. 2015, 46, 248-257. [CrossRef]

17. Japan Ergonomics Society. The Universal Design Practical Guidelines; Kyoritsu Shuppan Co., Ltd.: Tokyo, Japan, 2007.

18. Clarkson, P.J.; Coleman, R. History of Inclusive Design in the UK. Appl. Ergon. 2015, 46, 235-247. [CrossRef]

19. Story, M.F. Maximizing usability: The principles of universal design. Assist. Technol. 1998, 10, 4-12. [CrossRef]

20. Iwarsson, S.; Ståhl, A. Accessibility, usability and universal design-Positioning and definition of concepts describing personenvironment relationships. Disabil. Rehabil. 2003, 25, 57-66. [CrossRef]

21. Takeishi, A.; Fujimoto, T. Modularisation in the auto industry: Interlinked multiple hierarchies of product, production and supplier systems. Int. J. Automot. Technol. Manag. 2001, 1, 379-396. [CrossRef]

22. Ulrich, K. The role of product architecture in the manufacturing firm. Res. Policy 1995, 24, 419-440. [CrossRef]

23. McAdams, D.A.; Kostovich, V. A framework and representation for universal product design. Int. J. Des. 2011, 5, $29-42$.

24. Petersen, C.J. House Beautiful: The Organized Home: Stylish Storage Solutions for Every Room; Hearst Books: New York, NY, USA, 2008; p. 222.

25. Bjork, E. Many become losers when the universal design perspective is neglected: Exploring the true cost of ignoring universal design principles. Technol. Disabil. 2009, 21, 117-125. [CrossRef] 
26. Kostovich, V.; McAdams, D.A.; Moon, S.K. Representing user activity and product function for universal design. In Proceedings of the International Design Engineering Technical Conferences and Computers and Information in Engineering Conference, San Diego, CA, USA, 30 August-2 September 2009; Volume 49057, pp. 83-100. [CrossRef]

27. Wood, K.L.; Jensen, D.; Bezdek, J.; Otto, K.N. Reverse engineering and redesign: Courses to incrementally and systematically teach design. IJEE 2001, 90, 363-374. [CrossRef]

28. Hirtz, J.; Stone, R.B.; McAdams, D.A.; Szykman, S.; Wood, K.L. A Functional Basis for Engineering Design: Reconciling and Evolving Previous Efforts. Res. Eng. Des. 2002, 13, 65-82. [CrossRef]

29. Story, M.F. 7 defining criteria: A set of seven principles developed by the Center for Universal Design can help designers make their designs universal. Innov.-Mclean Va. 1997, 16, 29-32.

30. Nippashi, N.; Aoki, M.; Otake, S.; Kishi, C.; Terauchi, F. New concept and its methods of designing with ordinary citizensdesign for OURSELVES. In Proceedings of the 2nd International Conference for Universal Design in KYOTO, Kyoto, Japan, 22-26 October 2006.

31. Hoehle, H.; Aljafari, R.; Venkatesh, V. Leveraging Microsoft's Mobile Usability Guidelines: Conceptualizing and Developing Scales for Mobile Application Usability. Int. J. Hum. Comput. Stud. 2016, 89, 35-53. [CrossRef]

32. Bloch, P.H. Seeking the ideal form: Product design and consumer response. J. Mark. 1995, 59, 16-29. [CrossRef]

33. Ferketich, S.; Muller, M. Factor analysis revisited. Nurs. Res. 1990, 39, 59-62. [CrossRef]

34. Field, A. Discovering Statistics Using SPSS; Sage Publications: Los Angeles, CA, USA, 2009.

35. Tabachnick, B.G.; Fidell, L.S.; Ullman, J.B. Using Multivariate Statistics; Pearson: Boston, MA, USA, 2007.

36. Nunnally, J.C. Psychometric theory. Am. Educ. Res. J. 1978, 5, 83.

37. Nakagawa, S. (Ed.) Textbook for Universal Design; Long Sea Int'1 Book Co.: Taipei, Taiwan, 2006.

38. Beecher, V.; Paquet, V. Survey instrument for the universal design of consumer products. Appl. Ergon. 2005, 36, 363-372. [CrossRef]

39. Mougenot, C.; Bouchard, C.; Aoussat, A.; Westerman, S. Inspiration, images and design: An investigation of designers' information gathering strategies. J. Des. Res. 2008, 7, 331-351. [CrossRef] 